\title{
Green Innovation and Internationalization in Taiwanese Small and Medium Enterprises
}

\author{
Michael Yao-Ping Peng* \\ Business School, Yango University, China. \\ * Corresponding author. Tel.: +86 13060641100; email: s91370001@mail2000.com.tw \\ Manuscript submitted April 12, 2019; accepted January 5, 2020. \\ doi: 10.17706/ijeeee.2020.10.2.174-181
}

\begin{abstract}
Taiwan is one of the fastest growing economy in Asia region. In Taiwan, SMEs sector is a key component of the economy, accounting for $98.1 \%$ of all total business establishments. This study will explore the extent of Green Innovation initiatives by Taiwanese SMEs to leverage itself in achieving product competitive advantage and in internationalizing their venture. To explore the proposed conceptual model, which includes environmental resources, environmental cost and technology usage as independent variable and internationalization as dependent variable, SMEs from multiple industries are included in the sampling frame. Findings show environmental cost is the main determinant of product competitive advantage that influences Taiwanese SMEs internationalization.
\end{abstract}

Key words: Green innovation, competitive advantage, and internationalization.

\section{Introduction}

Taiwan is one of the fastest growing economy in Asia region. Economic growth, industrialization and growing population in developing countries such as Taiwan, demand a huge growth for renewable energy as global environmental problems call for drastic cut on fossil fuel consumption. This phoenomena arouses business to care on environmental issue, lead the business toward sustainability and Green Innovation. It has results in the promotion of green technology that presents the most viable way of meeting with the new green-related activities for environmental conservation. One of the plausible reason for the sustainable growth for the past decade could be associated with viable policies by the government that encourage private investment locally and aborad. In Taiwan, SME sector is a key component of the economy, accounting for $98.1 \%$ of all total business establishments. Besides that, Small and Medium Enterprises (SMEs) have taken wider and broader steps to increase their competitiveness in the world market by producing globally accepted products with greater branding and marketing strategies [1]. These capabilities are identified as international business capabilities (IBC) by Knight and Kim [2]. On the other spectrum of business sustainablity, there are researchers continually embarking on Green Innovation concepts in decision making process, making the world more sustainable for future generations and minimising the possible repercussions of poor implementation of Green Innovation. By the same time, business stakeholders started to concern on the environmental issues. It is interesting to know that the green mangement is yet to be fully understood by researchers, individuals, goverment agencies and private organizations, as some relates the incoporation of a business-wide recycling program as Green Innovation [3]. 
As preserving the world becomes the responsibility of each of the inhabitants in this world, and more heavier responsibiliteis to business owners, the whole concept of Green Innovation has to be tied to the ever growing business decisions that impacts the world. As the globalization of business activities becoming rampant where SMEs play a vital role, this study will explore the extent of Green Innovation initiatives by SMEs in Taiwan as part of their internationalization strategies. There are several reasons that influence Green Innovation in SMEs towards internationalization. More and more people evaluate a business from green aspect, it makes Green Innovation become a factor that influence SMEs internationalization, and SMEs must always be alert with today's environmental agenda in order to success in global business. Therefore, environmental issues must be handled and improved by new emergence of environmental performance. From Anderson [4], rising to meet environmental challenge will help the organozation to operate in a clean and environmentally-friendly way and become sustainable, but requires the company to make some major changes regarding the organization's strategy, process and structure.

As the concept of sustainability and pollution problem emerged as hot issues nowadays, it awaken the society's mind to carry out social responsibility and take care on the environment. , more consumers are evaluating a business through the green perspective. As well as business, they are motivated to reduce pollution, by the same time, they wish to cut cost in operation. The research intends to study is that Green Innovation can help SMEs in internationalization process, and which aspect contribute the most? By using Green Innovation competitive advantage as a mediating variable, it is influenced by a few factors that would affect on internationalization of SMEs. By finding and understanding the factors contributed on Green Innovation competitive advantage, it will provide added information to further improve the internationalization of SMEs. The results from the research can be used to help Taiwanese SMEs in internationalization, improve their competitiveness advantage and then promote the Green Innovation among SMEs. At the same time, it can give guidance to Taiwanese SMEs on which aspects to focus on to improve their competitiveness, arouse the awareness of SMEs on importance of Green Innovation.

\section{Literature Review}

The green movement has become the part of corporate social responsibility of many organization and they are now targeting to become a socially responsible corporation. Research on SMEs and the environment has often stressed their poor environmental performance, and barriers to greening have been a major focus of research. Barriers highlighted have included lack of resources and lack of awareness of their own ecological footprint or responsibility to protect the environment. Concern for the environment among SMEs has increased in recent years. Building upon the original resource-based view of the firm which contends that a firm's unique resources and capabilities are the main sources of competitive advantage [5], [6], and natural environment as source competitive advantage, international business competencies (IBC) required by firm [2], and the need for other sources of competitive advantage for SMEs such as Green Innovation [1]. The competitive advantage model is usually used traditionally to explain the sources of competitive advantage namely, product, technology and service quality [6].

\subsection{SMEs and Green Innovation}

Haden, Oyler, \& Humphreys [3] exploratory analysis on the Green Innovation is an important milestone to further understand the historical, practical, and theoretical perspectives on Green Innovation. One of the biggest issues facing the corporation that attempt to be environmentally responsible is that no one know what green really means. In order to succeed green process management system, it requires collaboration of inter-organizational relationship. Green process management has become more popular due to environmental regulations and corporate social responsibility. Green process management approaches prevent potential waste, reduce the consumption of raw materials, and decrease pollution. A number of 
studies have presented evidences that green process management positively affect minimizing harmful waste and lengthening the life cycle of the product or material [7]. Also, corporate environmental management is defined as business managerial activities or strategies that comply with the environmental regulation, implemented to attain the environmental goal and continuously improvement in environmental performance [8]-[10]. Firms that practice the proactive environmental management strategies could solve the environmental problem by collaborating with the different departments and integrate the objectives of environmental, utilizing the innovative environmental technology [11].

\subsection{Green Innovation and Competitive Advantage}

The issue of the impacts of environmental protection on corporate competitive advantages was not paid much attention by academic communities until recently. The companies always try to avoid environmental protection investments and think they do not only have no benefit for corporations but also hinder the future development of corporations. Many companies thought corporate environmental management as an unnecessary investment, or even were misled that this would obstruct the development of the corporations. Businesses can increase the productivity of resources through green innovation. Moreover, the corporations that pioneer in green innovation will enjoy the "first mover advantage", which allow them to ask for a higher price for green products and, at the same time, improve their corporate images, develop new markets and gain competitive advantages (Hart, 1995). Porter [6] and Barney [5] defined competitive advantages of a company as a strength or strategy which is high cost of imitation for competitors, or, even implemented by competitors, they will not enjoy the same benefit as much as the company do. As environmental sustainability has become an important competitive source, implementing green supply chain management (GSCM) is now a concern for most business organizations. More recently, firms are being increasingly pressured to consider environmental issues in their supply chains. A growing number of organizations realize that to simultaneously achieve their environmental goals and competitive advantage, they need to manage their supply chain with green initiatives by looking beyond their own facilities. Rao \& Holt [12] shows that by carry out greening steps in different phase of supply chain and integrate into "Green Supply Chain", it results positive impacts on competitiveness and economic performance. By improving environmental performance and product differentiation, cost leadership as well as differentiation can be operationalized in environmental practice [6].

\subsection{Environmental Resource}

Environmental resource may exist as a separate entity such as fresh water, and air, as well as a living organism such as a fish, or it may exist in an alternate form which must be processed to obtain the resource such as metal ores, oil, and most forms of energy. Environmental resource management is "a purposeful activity with the goal to maintain and improve the state of an environmental resource affected by human activities". It is not, as the phrase suggests, the management of the environment as such, but rather the management of the interaction and impact of human societies on the environment. Environmental resources management aims to ensure that ecosystem services are protected and maintained for equitable use by future human generations, and also, maintain ecosystem integrity as an end in itself by taking into consideration ethical, economic, and scientific (ecological) variables. Few most well-known methods in environmental resource management reuse, reduce and recycling. According to [13] and [4] the steps focus upon the production process itself and require the organization to uncover the ways to eliminate harmful emissions, create and utilize renewable energy and redesign products and processes for recycling. Companies that wish to move towards green should first start with these. 


\subsection{Environmental Cost}

In the Wateco guidance's glossary of terms, "Environmental costs are defined as representing the costs of damage that impose on the environment and ecosystems and those who use the environment (e.g. a reduction in the ecological quality of aquatic ecosystems or the Stalinisation and degradation of productive soils)." Environmental costs are costs connected with the actual or potential deterioration of natural resources due to economic activities. Environmental cost includes the expenditures incurred to prevent, contain, or remove environmental contamination. Porter and van der Linde [14], the environment protection cost will be paid off and results in bottom line performance improvement. Christmann [15] points out the potential benefits of specific Green Innovation practices in achieving low cost and differentiation advantages. With the consumers become eco-conscious, the organizations are realizing the importance of becoming green to capture the market share. To become green, the organizations are implementing all sorts of environmental friendly practices and are reporting it in their corporate social responsibility report.

\subsection{Technological Usage}

The green technology definition, in simple words, it means the technology which is environmentally friendly, developed and used in such a way so that it doesn't disturb our environment and conserves natural resources. Organizations are investing in green IT initiative to help them become a more responsible organization towards the environment. Many software organizations have build a sustainable or green information technology framework in an effort to reduce carbon footprints. Carbon footprint is the measure of the amount of greenhouse gases, measured in units of carbon dioxide, produced by human activities. A carbon footprint can be measured for an individual and also for an organization. The reason for sudden interest by the organizations to reduce the carbon footprint is the 'green regulation' which is formulated by international environmental agencies. The 'green' regulation like Restriction of Hazardous Substances (RoHS) and Waste Electrical and Electronic Equipment (WEEE) were formulated by European Union in an effort to become more environmental friendly. This regulation also addresses the recycling programs for the manufacturer's products. Leading software organizations like IBM, Cisco, Dell HP and Fujistu have taken steps to save on energy consumption by "facility upgrades, power management strategies and IT efficiency solutions" and they have committed to reduce the green house gas emissions by 40 percent. Green IT, it has become the 'in' thing for the organization to gain competitive advantage.

\subsection{Internationalization}

In economics, internationalization has been viewed as a process of increasing involvement of enterprises in international markets, although there is no agreed definition of internationalization or international entrepreneurship. Another researcher that was influenced by economics was Vernon [16]. In his famous product life cycle theory, he described internationalization as something that occur when companies develop new products and starts to export the products to new markets. When demand in a host market increase, the company invests in production facilities in that market. As the product become more and more standardized, and sold in more and more markets, the company will begin to take advantage of low cost production in certain markets. Behavioral theory is another area which has influenced several internationalization theories. In their internationalization process model Johanson \& Vahlne [17] describe internationalization as something that is developed in small steps. As firms gain market knowledge, they are able to commit more to the foreign market. Some researchers explain 'internationalization' as the 'outward movement in a firm's international operations [18]. This common feature has been broadened further by Johanson \& Vahlne [17] described internationalization of the firm as a sequential and orderly process in which firms gradually increase their international involvement and the associated changes in organizational forms. 
However, in today's marketplace the advances in technology and changing economic markets, internationalization no longer can be identified as a traditional, incremental process anymore [19]. As a result, a new topic in the internationalization literature has arisen in the last decade and focuses on international new ventures (INVs) and/or born-globals which are, by theoretic definition, small start-ups internationalizing at inception or very shortly thereafter [19].

The theoretical framework used for this research is shown as in Fig. 1:

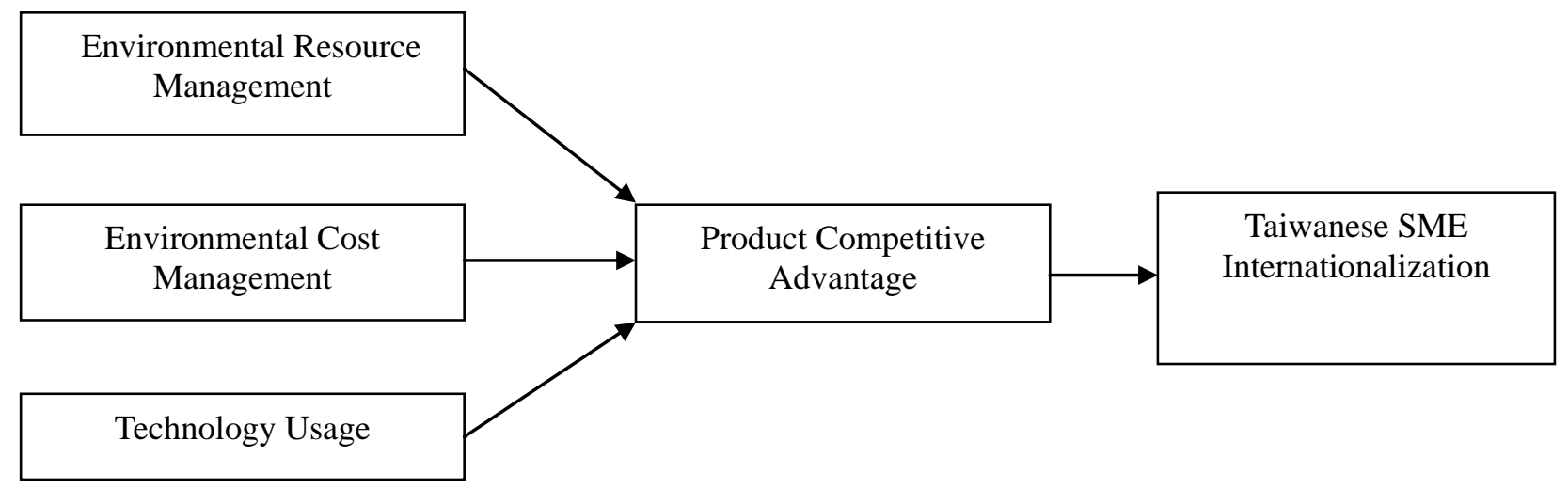

Fig. 1. Conceptual framework.

\section{Methodology}

\subsection{Sampling and Participants}

Data for this study was collected through structured questionnaires. The questionnaires were distributed to SMEs in Taiwan. The sample randomly selected from Taiwanese SMEs which involve internalization. The respondents (i.e., executives, CEOs and upper-level managers with a strategic responsibility for their firms) assumed to be knowledgeable and familiar with the operations related to the issues under investigation. 245 were returned, for a $24.5 \%$ return rate.

\section{Analysis and Results}

\subsection{Measurement Results}

The reliability test on the multi-item instrumentals is the first test carried out on the data used in this research. The Cronbach's Alpha value was used to test the reliability of the items measuring each variable: Taiwanese SME internationalization (INT), Environmental Resource Management (ER), Environmental Cost Management (EC), Technological Usage (TU) and Product Competitive Advantage (PCA). It is a reliability measure coefficient that proves how well items in a set are positively correlated to one another. The result obtained as shown in Table 3 All the Conbach's Alpha value of variables was higher than 0.5 and accepted based on the minimum Cronbach's alpha value of 0.50. All variable have Cronbach alpha values greater that 0.60 and indicates inter - item consistency. None of the items were deleted in the test because the reliability of interterm was high.

Table 3. Summary of Reliable Analysis

\begin{tabular}{|l|l|l|l|}
\hline Variable & No. of item & Item deleted & Alpha \\
\hline Taiwanese SME Internationalization (INT) & 5 & - & 0.885 \\
\hline Environmental Resource Management (ER) & 5 & - & 0.690 \\
\hline
\end{tabular}




\begin{tabular}{|l|l|l|l|}
\hline Environmental Cost Management (EC) & 8 & - & 0.827 \\
\hline Technological Usage (TU) & 8 & - & 0.843 \\
\hline Product Competitive Advantage (PCA) & 9 & - & 0.866 \\
\hline
\end{tabular}

\subsection{Main Effect Analysis of the Structural Model}

In this study, the structural model is established for the measurement model of each potential variable mentioned above according to the research structure, and the mode fit of the structural equation model examining theory is adopted. As the results shown, the structural model provided good fit to the data: $\chi 2 / \mathrm{df}=2.352$; Tucker-Lewis Index (TLI) = .994; Comparative Fit Index (CFI) = .995; Standardized Root Mean Square Residual $($ SRMR $)=.042$; Root Mean Square Error of Approximation (RMSEA) $=.043$. In conclusion, the model fit in this paper should be acceptable.

In this study, SEM is used to detect the relationship between variables in the model, and there are many items in the consideration of certain facet scales. The results of the study are shown in Figure 2. All the correlations among use intention, attitude toward use, perceived ease of use and perceived usefulness are positively statistical significance, so all paths were supported.

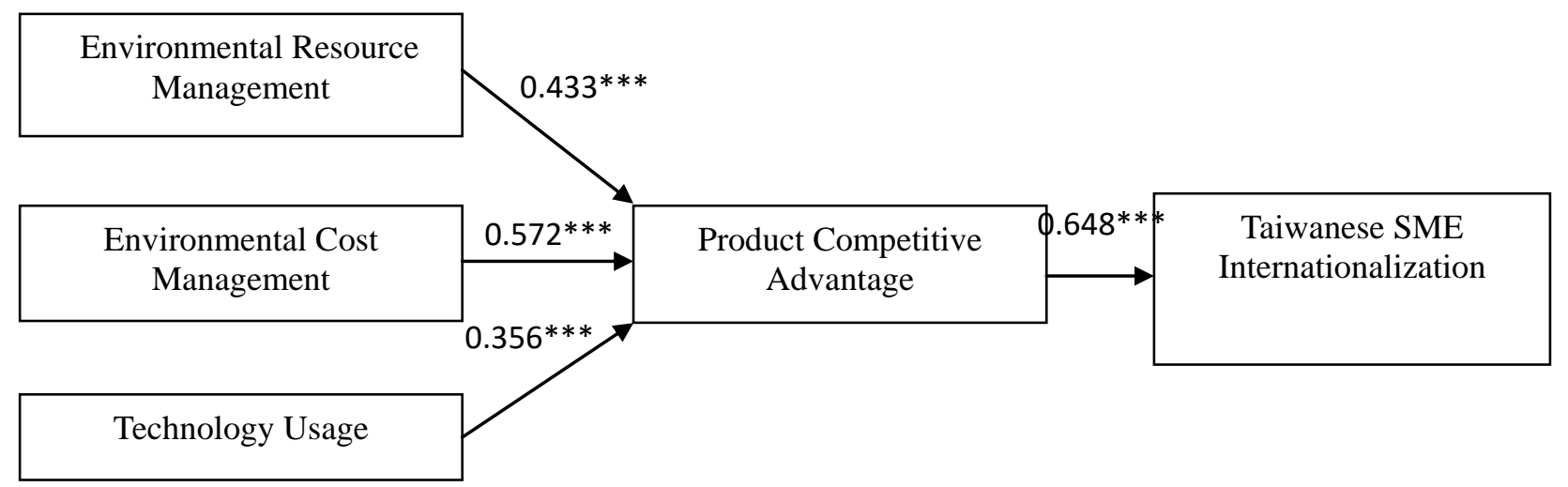

Fig. 2 Path analysis.

\section{Conclusions and Discussions}

Nowadays, more and more countries are paying attention on the sustainability issues and thus, require business to follow certain green standards to reduce pollution, for example ISO 14001. Same happening in European Union and United States, they are even more strict in sustainability assessment, such as Waste electrical and electronic equipment (WEEE) regulations mean that manufacturers, sellers and distributors are responsible for taking back and recycling unwanted electrical and electronic equipment. Most of the importing trading partners of them are developing countries. Thus, if any company wants to enter to their market, they will have to apply Green Innovation. Besides, consumers are growing in awareness of sustainability issue. Under the market pressure, this urges and motivates companies to adopt Green Innovation for company's brand image and market positioning. As a supplier, they need to reach certain green standard in order to comply with the requirement of client, especially the foreign company.

From the research, only the environmental cost management (EC) supported the literature review, it has the positive relationship with product competitive advantage and Taiwanese SME Internationalization. This is somehow related to the type of industry involved by the respondents. In food manufacturing industry, company seldom recycle the wastage due to hygienic purpose. Also they usually don't buy their inventories 
from organic supplier because the price is higher. If they are doing so, they will lose the product competitiveness due to the higher price. Food manufacturing industry does not really implement high technology such as automotive, internet, technology and communication (ICT), medical and chemical.

\subsection{Implications}

From the result of the research, we can know the aspect of environmental cost is the main determinant in Green Innovation as product competitiveness advantage and leads company to the direction of internationalization. Thus, it provided an insight that SMEs should first focus on environmental cost aspect, then increase the product competitiveness in order to go international. By the same time, the management team should pay more effort on the environmental resource and technology usage as well. Definitely, by doing so, it will gain benefits for SMEs, not only in term of product competitive advantage, but also the corporate social responsibility and the business sustainability. Especially SMEs in food and product manufacturing industry, they play an important role in protecting the environment of the country, because they made up more than a half of the industry. As the world now is going to get more polluted, SMEs and other companies as part of the earth citizen, we should do something for the mother of Earth; return a green environment to our next generation. This concept is becoming more and more popular and widely carried out by consumers, who are one of the most important stakeholders of company. They are more concerning in company's green performance, same also for government and society, even more and more world well-known company like Nike, Adidas, Pepsi-Cola are involved in Green Innovation. Become green is no more a trend, but a must in the future.

\section{Conflict of Interest}

The authors declare no conflict of interest.

\section{Author Contributions}

Michael Yao-Ping Peng conducted the research, analyzed the data, and wrote the paper.

Funding: This paper is supported by Fujian Province Social Sciences Plan Project in 2019 (Grant No. FJ2019B106).

\section{References}

[1] Shankar, C., Mohamed, S., \& Jayaraman, M. (2011). The role of corperate entrepreneurship in internationalization of small and medium entreprises. The International Journal of Interdisciplinary Social Sciences, 5(9), 506-516.

[2] Knight, G. A, \& Kim, D. (2009). International business competence and the comtemporary firm. Journal of International Business Study, 255-273.

[3] Haden, O., \& Humphreys. (2009). Historical, practical and theoritical perspective on green innovation. Management Decision, 47(7), 1041-1055.

[4] Anderson, R. (2004). Climbing Mount Sustainability. Quality Progress, 37(2), 32-37.

[5] Barney, J. (1991). Firm resource and sustained compatitive advantage. Journal of Management, 3-17.

[6] Porter, M. (1980). Competitive Strategy, Technique For Analyzing Industries and Competitor. New York: The Free Press.

[7] Linton, J. D., Klassen, R., \& Jayaraman, V. (2007). Sustainable supply chains: An introduction. Journal of Operations Management , 25, 1075-1082.

[8] Berry, M. A., \& Rondinelli, D. A. (1998). Proactive corporate environmental management: A new industrial. Academy of Management Executive, 12(2), 36-50.

[9] Chen, Y.-S. (2008). The positive effect of green intellectual capital on competitive advantages of firms. 
Journal of Business Ethics, 77(3), 268-86.

[10] Chen, Y.-S. (2008). The driver of green innovation and green image - green core competence. Journal of Business Ethics, 81(3), 530-45.

[11] Greeno, L. J., \& Robinson, S. N. (1992). Rethinking corporate environmental management. Columbia Journal of World Business, 27(3/4), 220-34.

[12] Rao, P., \& Holt, D. (2005). Do green supply chains lead to competitiveness and economic performance? International Journal of Operations \& Production Management, 25(9), 898-916.

[13] McClenahen, J. (1998). Modest man, ambitious mission. Industry Week, 247(2), 68-69.

[14] Porter, M. E., \& Linde, C. (1995). Toward a new conception of the environment-competitivenessrelationship. Journal of Economic Perspectives, 9(4), 97-118.

[15] Christmann, P. (2000). Effects of best practices of environmental management on cost advantage. Academy of Management Journal, 43(4), 665-680.

[16] (1966). International investment and international trade in the product cycle. Quarterly Journal of Economics, 41(4), 255-67.

[17] Johanson, J., \& J.-E. Vahlne. (1977). The internationalization process of the firm - A model of knowledge development and increasing foreign market commitments. Journal of International Business Studies, 81), 23-32.

[18] Johanson, J., \& Wiedersheim-Paul, F. (1975). The internationalization of the firm - Four Swedish cases. Journal of Management Studies, 12(3), 305-322.

[19] Oviatt, B. M., \& McDougall, P. P. (1994). Toward a Theory of International New Ventures Journal of International Business Studies, 25(1), 45-64.

Copyright (C) 2020 by the authors. This is an open access article distributed under the Creative Commons Attribution License which permits unrestricted use, distribution, and reproduction in any medium, provided the original work is properly cited ( $\underline{\text { CC BY 4.0). }}$.

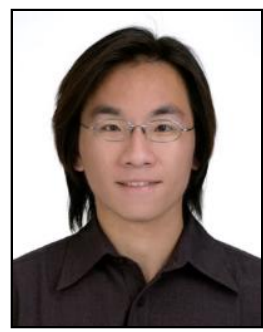

Michael Yao-Ping Peng is an associate professor in School of Management, Xi'an University of Architecture and Technology in China. He was finishing his Ph.D. program in the Department of Business Administration in National Chung Hsin University. His major includes marketing management, international business, institutional research, etc. 